\title{
Childhood Tomboyism and Adult Androgyny
}

\author{
Shawn Meghan Burn, A. Kathleen O'Neil, and Shirley Nederend
}

Female university and community college students $(\mathrm{N}=194)$ completed the Bem Sex-Role Inventory and a 12-item tomboyism index. Subjects were predominantly Euro-American (71\%). A multiple regression analysis was used to test the prediction that androgyny and masculinity would significantly predict tomboyism scores. The proportion of variance in tomboyism accounted for by masculinity was significant, but once masculinity was entered, no additional predictive value was added by the entry of androgyny or femininity. Tomboyism was not related to the development of expressive qualities such as compassion and sensitivity to the needs of others. However, tomboyism was positively related to some desirable instrumental qualities such as assertiveness and self-reliance. Tomboyism was common and generally declined at puberty due to social pressure.

In 1977, Hyde et al. noted that the research on tomboyism was meager and was based on the assumption that tomboyism is rare and abnormal. They found, however, that $51 \%$ of the adult women in their study identified themselves as childhood tomboys, and $63 \%$ of a sample of females entering seventh, eighth, and ninth grades did so as well. Plumb and Cowan (1984) found that $52 \%$ of an age-mixed sample (fourth to tenth graders and an adult community college sample) stated that they were or had been tomboys. Unfortunately, the research on tomboyism remains meager although some psychological researchers view tomboyism positively because they believe it leads to androgyny (cf. Hemmer \& Kleiber, 1981; Plumb \& Cowan, 
1984). The rationale underlying this hypothesis is that tomboys engage in both female and male play behaviors, and receive greater exposure to social environments requiring both instrumental and expressive behaviors.

Bem (1974) pointed out that masculinity and femininity do not exist as polar opposites and that it may be desirable to possess both, that is, to be androgynous. Research links androgyny to situational flexibility (Vonk \& Ashmore, 1993); high self-esteem (Mullis \& McKinley, 1989); achievement motivation (Spence \& Helmrich, 1978); parental effectiveness (Baumrind, 1982); subjective feelings of well-being (Lubinski et al., 1981); and marital satisfaction (Zammichieli et al., 1988). However, some studies indicate that it is masculinity, and not femininity or androgyny, that is more strongly related to a positive self-esteem and adjustment (Basoff \& Glass, 1983; Taylor \& Hall, 1982). This may be because masculine attributes are viewed more positively and consequently lead to greater social rewards (Cook, 1985; Unger \& Crawford, 1992; Whitely, 1983).

There is some concern that the terms femininity and masculinity promote gender stereotypes and differences (Betz, 1993). Therefore, some psychologists recommend that instead we use the term "instrumentality" to refer to self-assertion and competence (aspects of traditional masculinity), and the term "expressiveness" to refer to qualities such as interpersonal concern and emotional expressiveness (aspects of traditional femininity) (Spence \& Helmrich, 1981).

Culture and social norms are believed to affect the acceptability of tomboyism behavior. Plumb and Cowan (1984) found tomboyism to decline at puberty. Martin (1990) suggests that the acceptability of tomboyish behavior is partly because of the expectation that tomboys will "grow out of it." Such an expectation may lead to increased social pressure to do so at puberty. Hyde (1991) suggests that tomboyism cessation at puberty occurs because of the intensification of gender-role pressures. If there are greater social rewards for traditional female-role behavior at puberty, and females want social rewards in order to feel accepted, then it follows that tomboyism would decline at puberty. The physical changes that occur with puberty may also play a role. Perhaps menstruation and the development of secondary sex characteristics (in particular the development of breasts), increase the saliency of the tomboy's femaleness to herself and others. This, in turn, may increase the saliency of female gender norms with regard to the tomboy's behavior. The tomboy then self-regulates her behavior accordingly. Peers and adults further encourage her conformity to the female role out of the belief that it is time she leave behind her tomboy ways.

In the study described below, female college students completed the BSRI and a survey designed to measure childhood tomboyism. The age at which tomboyism stopped and the reasons why were also measured. It was 
predicted that androgyny and masculinity as measured by the BSRI would be significant predictors of tomboyism scores, that tomboyism would be common, that respondents would report the decline of tomboyism at puberty, and that social pressure and physical changes would be cited as the main reasons for the cessation of tomboyism.

\section{METHOD}

\section{Subjects}

Subjects were 194 female university $(n=103)$ and community college students $(n=91)$ from general education introductory psychology and history classes. Age ranged from 17 to $51(M=22)$. Subjects were predominantly Euro-American (70.6\%); $11.9 \%$ were Hispanic; $5.2 \%$ Asian; $4.1 \%$ "mixed"; $2.6 \%$ South Pacific Islander; $2.1 \%$ "other"; $1 \%$ African American; $.5 \%$ Native American; and $2.1 \%$ declined to answer the ethnicity question. Fifty-five different college majors were represented in the sample.

\section{Materials}

Bem Sex-Role Inventory (BSRI). The BSRI (Bem, 1974) was used to provide each subject with three scores: masculinity, femininity, and androgyny. Subjects rated themselves on 60 adjectives using a 7-point scale anchored at one end with "almost never true of me" (1) and "always or almost always true of me" (7) at the other. Subjects' femininity and masculinity scores were calculated by adding ratings across the 20 feminine adjectives and 20 masculine adjectives respectively. Androgyny was a product of the subject's masculinity and femininity scores (femininity score $\times$ masculinity score). This procedure is explained at the beginning of the results section.

Tomboy Index. The 12-item Tomboy Index was developed following a pilot survey based on Plumb and Cowan's (1984) study of tomboy activity preferences, Hyde et al.'s (1977) tomboy study, and informal interviews conducted to determine what people considered to be typical tomboy behaviors. We found that self-identified tomboys and others thought of tomboyism primarily in terms of preferring less feminine clothes, games, and toys, and playing with boys on a regular basis. The pilot survey was administered to 24 female students in an undergraduate research methods class who were instructed to judge the face validity, answer the questions, and critique question content and wording. Based on these responses, the index was revised. 
The summed Tomboy Index consists of 12 items rated with a 7-point scale anchored by "Not at all true of me" (1) and "Very true of me" (7) (a "don't remember" option was also provided). Cronbach's alpha was .88 indicating that the index is highly internally consistent. Test-retest reliability at three weeks was .91 . Scores on the index were significantly positively correlated $(r=.79, p<.001)$ with a single item, "On a scale of Tomboyism, how would you rate yourself as a child?" (7-point scale, $1=$ not at all a tomboy, $7=$ very much a tomboy) indicating high concurrent validity. The items were as follows (all were preceded by "Before age 12, I . ."): (1) preferred shorts/jeans to dresses; (2) preferred traditional boys' toys (e.g., guns, matchbox cars) over girls' toys (e.g., dolls); (3) resembled a boy in appearance; (4) wished I was a boy; (5) preferred traditionally boys' activities (e.g., climbing trees, playing army) over traditionally girls' activities (e.g., ballet, playing dressup); (6) had girl friends that were tomboys; (7) participated in traditionally male sports (e.g., football, baseball, basketball) with boys; (8) was loud or boisterous in my play with others; (9) preferred playing with boys over girls; (10) used traditionally girls' toys in traditional boys' activities (e.g., Barbie driving a Tonka truck); (11) engaged in rough and tumble play; (12) played with many different peer groups (e.g., tomboys, non-tomboys, boys).

Subjects were also asked, "If you consider yourself to have been a tomboy as a child, at what point or age did you stop behaving like one? (put NA for nonapplicable if you weren't a tomboy)." This was followed by the open-ended question, "What made you stop being a tomboy?"

\section{Procedure}

The Tomboy Index and the BSRI were distributed to female students by one of four female undergraduate research assistants who were given a standard set of administration instructions. Subjects were verbally instructed, as well as in written form, that their participation was voluntary and anonymous, that the survey's purpose was to find out about tomboyism, and that the study results would be made available to them within a few weeks (a written summary of results was provided to instructors for distribution to subjects three weeks later). Participants were thanked for their participation.

\section{RESULTS}

As noted by Hargreaves et al. (1981), the four-way classification procedure customarily used in androgyny research results in a loss of infor- 
Table I. Statistically Significant Correlations

Between Tomboyism Scores and BSRI Adjective Ratings

\begin{tabular}{lc}
\hline \multicolumn{1}{c}{ Adjective } & Pearson $r$ \\
\hline 1. Masculine & $.53^{c}$ \\
2. Athletic & $.51^{c}$ \\
3. Feminine & $-.42^{b}$ \\
4. Willing to Take Risks & $.35^{c}$ \\
5. Aggressive & $.30^{c}$ \\
6. Competitive & $.26^{c}$ \\
7. Assertive & $.25^{b}$ \\
8. Forceful & $.25^{a}$ \\
9. Childlike & $.21^{b}$ \\
10. Individualistic & $.21^{b}$ \\
11. Soft-Spoken & $-.20^{a}$ \\
12. Willing to Take a Stand & $.20^{a}$ \\
13. Self-reliant & $.19^{b}$ \\
14. Leadership Abilities & $.18^{a}$ \\
15. Dominant & $.17^{a}$ \\
\hline${ }_{p}<.05$. & \\
${ }_{p} p<.01$. & \\
${ }^{c} p<.001$. &
\end{tabular}

mation from the separation of subjects based on median splits, and the need to assume that femininity and masculinity are independent dimensions. Another problem has been what to do with the "undifferentiated" group who scores low on both the masculine and feminine adjectives. One solution to these problems is the use of multiple regression analysis where androgyny is the product of a subject's femininity and masculinity scores (Hargreaves et al., 1981). Androgyny, masculinity, and femininity can then used as predictor variables in the regression equation. In our case, the dependent variable was tomboyism as measured by scores on the tomboyism index.

Masculinity was entered first into the regression equation because the Pearson $r$ between it and tomboyism was higher $(r=.43, p<.001)$ than the $r$ 's between tomboyism and femininity $(r=-.11, p>.05)$ and tomboyism and androgyny $(r=.29, p<.001)$. Additionally, tomboyism was expected to have a greater influence on masculinity given that tomboyism was largely defined in terms of the number of traditionally boy activities engaged in. The proportion of variance in tomboyism accounted for by masculinity was significant, $F(1,152)=35.21, p<.001$. However, once masculinity was entered, no additional predictive value was added by the entry of androgyny or femininity.

An additional multiple regression was performed to test for the possibility of a curvilinear relationship between tomboyism and androgyny. In 
other words, was there evidence that "moderate" levels of tomboyism would lead to the greatest androgyny scores because moderate tomboyism involves greater balancing of female and male activities? Following the recommendations of Cohen and Cohen (1975, pp. 214-215), a regression was conducted to see if the quadratic term (tomboyism scores squared) accounted for any additional variation in androgyny over the linear term. It did not (the $r^{2}$ change was .01, ns).

Table I shows those BSRI adjectives for which a significant Pearson correlation coefficient with the tomboyism index was obtained. Of the 40 adjectives, 15 were significantly related to tomboyism at the .05 level. Of those 15,12 were "masculine" (i.e., used to compute the masculine score in a traditional median-split BSRI scoring), and were positively related to tomboyism. Of the three significant "feminine" adjectives, two were negatively related to tomboyism (feminine and soft-spoken) and one was positively related (childlike).

Subjects were asked, "if you consider yourself to have been a tomboy as a child, at what point or age did you stop behaving like one?" (they were asked to put "NA" if they weren't a tomboy, an option selected by $50 \%$ of the subjects). Of the $97(50 \%)$ who answered the question, $14(7 \%)$ reported that they never stopped being a tomboy. Of those who gave an age, the minimum was 8 and the maximum 17, with a mean of 12.76 and a standard deviation of 1.88 .

Subjects were also asked to respond to the open-ended question: "What made you stop being a tomboy?" Open-ended responses were classified into categories to the extent possible. Three of the four categories suggest the role of social norms in their cessation of tomboyism. For instance, one of the more frequent reasons (given by 21 subjects) was social pressure from junior or high school peers. Examples include "Friends said stuff about me always being with the guys instead of the girls;" "Jr. high peers said I looked too much like a guy;" and "My female friends got me to change." A second common explanation was "wanted to attract boys" (provided by 20 subjects). Answers put in this category included, "I wanted to be more attractive to boys"; "Wanted to date boys;" and "interest in boys as boyfriends." Eight subject gave answers indicating that social pressure from parents/adults was responsible. These included such responses as "I needed to be a lady when talking to elders;" "My parents taught me I must behave as a girl;" "Father began treating me differently;" "Dad put emphasis on being a young lady;" and "Mother insisted I wear nice clothes." Responses of 11 subjects fell into a puberty/physical development category and included responses such as "Breasts;" "Menstruation;" "Guy neighbor held me in touchy way while playing basketball-caused me to withdraw;" and "A more feminine appearance from physical development." 
Some responses were unable to be easily categorized such as these: "Interested in school rather than sports;" "Was going into high school and wanted to be treated like a girl;" "I believe I just started to grow up and like different things;" "Other things became more interesting;" "Lost interest in those types of activities;" "The boys got bigger and I was unable to compete;" and "I got a brother."

\section{DISCUSSION}

The hypothesis that childhood tomboyism would be positively related to adult androgyny was not supported while the hypothesis that tomboyism would be related to adult masculinity was. Although the Pearson $r$ between androgyny and tomboyism was significant, results from the regression analysis indicate that this relationship was largely due to the influence of masculinity. Tomboyism was not positively or negatively related to the development of expressive qualities such as compassion and sensitivity to the needs of others. However, tomboyism was positively related to some desirable instrumental qualities such as assertiveness and self-reliance.

Most tomboys reported stopping tomboy-like behavior at puberty, a finding consistent with Plumb and Cowan (1984). The majority of openended responses to a question asking why childhood tomboys stopped being tomboys suggest that social information advocating conformity to the traditional female role is intensified at this time. This is consistent with Hyde's (1991) suggestion that severe gender role pressures for females do not occur until adolescence and Martin's (1990) contention that tomboyism is something one is expected to grow out of. One gender role pressure that occurs at puberty is the expectation that females attract boys. Many respondents indicated that a desire to attract boys was a factor in the cessation of their tomboyism. The physical development which accompanies puberty also appeared to be a factor. As suggested in the introduction, menstruation and development of secondary sex characteristics may increase the salience of the tomboy's femaleness to herself and others, and this may increase the application of female norms to her behavior. This emphasis on conformity to the traditional female role may be misguided. Helson and Picano (1990) found that while accepting the traditional female lifestyle led to increased well-being in early adulthood, it was associated with a decline in well-being by age 43 . They reason that this occurs because early conformity to the traditional role is socially supported and leads to high self-regard. Later, well-being declines due to dependence, putting her family's needs above her own, and feeling out of sync with current "career woman" norms. 
Consistent with earlier studies, we found self-reported tomboyism to be approximately $50 \%$. Tomboyism, then, is common despite the numerous social agents such as parents, peers, television, toy advertisements, etc. which communicate that gender-differentiated behavior is appropriate (see Burn, 1996 for a review of research on such social agents). It is possible that without social information, social pressure, and the wide availability of adults modelling sex-role appropriate behavior, the incidence of tomboyism would be even higher and would persist even longer. Alternatively, it is possible that the greater valuing of traditionally male behaviors and activities may be partly responsible for the high incidence of tomboyism and that in the absence of such greater valuing, the incidence of tomboyism would decline. Presumably under such a scenario, boys would engage in more "girl" activities as well.

The majority of subjects participating in this study were Euro-American and cross-cultural research on the relationship between tomboyism and androgyny is needed. For instance, if cultural tolerance of tomboyism is related to the incidence of adult androgyny, this would suggest that there is more to androgyny than individual temperament. Unfortunately, the small $n$ 's in the present study prevented exploration of ethnic differences. However, cross-cultural research on androgyny suggests that social factors play an important role in its development. LaFromboise et al. (1990) discuss how prior to European colonization, cross-sex behavior among Native Americans was respected and rewarded. Kranau et al. (1982) found that Mexican American women highly acculturated into American society had higher feminine scores on the Bem Sex Role Inventory (BSRI) than those less acculturated, although they exhibited fewer feminine behaviors. DeLeon (1993) found female African Americans and Puerto Ricans to be more androgynous than Euro-Americans. Other studies have found African American women to score higher in androgyny than Euro-American women (Binion, 1989; Dugger, 1988). This may be the result of the consistent presence of Black women in the labor force, leading to self-reliance, strength, resourcefulness, and autonomy (Dugger, 1988).

The hypothesis that childhood tomboyism leads to adult androgyny is compelling. After all, the activities that children engage in arguably affect the skills they learn and the psychological and interpersonal qualities they develop. However, due to the way tomboyism was operationalized in this study, the hypothesis that engaging in a variety of traditionally female and male play activities leads to the development of instrumental as well as expressive qualities remains unaddressed. Given that tomboyism was defined by the masculine play activities engaged in by subjects, perhaps it is not surprising that tomboyism was related to masculinity rather than androgyny. Future researchers may want to work with other conceptualiza- 
tions of tomboyism before we conclude that tomboyism and androgyny are unrelated. Similarly, the BSRI as a measure of androgyny is debatable, and examination of the tomboy-androgyny hypothesis should proceed with other measures of androgyny. In the meantime, this study suggests that the engagement of girls in what are thought of as traditionally boy activities is related to the possession of some desirable instrumental qualities in adulthood.

\section{REFERENCES}

Basoff, E. S., \& Glass, G. V. (1982). The relationship between sex roles and mental health: A meta-analysis of twenty-six studies. Counseling Psychologist, 10, 105-112.

Baumrind, D. (1982). Are androgynous individuals more effective persons and parents? Child Development, 53, 44-75.

Bem, S. L. (1974). The measurement of psychological androgyny. Journal of Consulting and Clinical Psychology, 42, 155-162.

Betz, N. (1993). Women's career development. In F. L. Denmark \& M. A. Paludi (Eds.), Psychology of women: A handbook of issues and theories. Westport, CT: Greenwood Press.

Binion, V. J. (1990). Psychological androgyny: A black female perspective. Sex Roles, 22, 487-508.

Burn, S. M. (1996). The social psychology of gender. New York: McGraw-Hill.

Cohen, J., \& Cohen, P. (1975). Applied multiple regression/correlation analysis for the behavioral sciences. Hillsdale, NJ: Erlbaum.

Cook, E. P. (1985). Psychological androgyny. New York: Pergamon.

DeLeon, B. (1993). Sex role identity among college students: A cross-cultural analysis. Hispanic Journal of Behavioral Sciences, 15, 476-489.

Dugger, K. (1988). Social location and gender role attitudes: A comparison of Black and White women. Gender and Society, 2, 425-448.

Hargreaves, D., Stoll, L., Farnworth, S., \& Morgan, S. (1981). Psychological androgyny and ideational fluency. British Journal of Social Psychology, 20, 53-55.

Helson, R., \& Picano, J. (1990). Is the traditional role bad for women? Journal of Personality and Social Psychology, 59, 311-320.

Hemmer, J. D., \& Kleiber, D. A. (1981). Tomboys and sissies: Androgynous children? Sex Roles, 7, 1205-1212.

Hyde, J. S. (1991). Half the human experience: The psychology of women (4th ed.). Lexington, MA: D. C. Heath \& Company.

Hyde, J. S., Rosenberg, B. G., \& Behrman, J. A. (1977). Tomboyism. Psychology of Women Quarterly, 2, 73-75.

Kranau, E. J., Green, V., \& Valencia-Weber, G. (1982). Acculturation and the Hispanic woman: Attitudes, sex-role behavior, and demographics. Hispanic Journal of Behavioral Sciences, 4, 21-40.

LaFromboise, T. D., Heyles, A. M., \& Ozer, E. J. (1990). Changing and diverse roles of women in American Indian cultures. Sex Roles, 22, 455-476.

Lubinski, D., Tellegen, A., \& Butcher, J. N. (1981). The relationship between androgyny and subjective indicators of emotional well-being. Journal of Personality and Social Psychology, $40,722-730$.

Martin, C. L. (1990). Attitudes and expectations about children with nontraditional and traditional gender roles. Sex Roles, 22, 151-165.

Mullis, R. L., \& McKinley, K. (1989). Gender-role orientation of adolescent females: Effects on self-esteem and locus of control. Joumal of Adolescent Research, 4, 506-516. 
Plumb, P., \& Cowan, G. (1984). A developmental study of de-stereotyping and androgynous activity preferences of tomboys, nontomboys, and males. Sex Roles, 10, 703-712.

Spence, J. T., \& Helmrich, R. (1978). Masculinity and femininity: Their psychological dimensions, correlates, and antecedents. Austin: University of Texas Press.

Spence, J. T., \& Helmrich, R. (1981). Androgyny vs. gender schema: A comment on Bem's gender schema theory. Psychological Review, 88, 365-368.

Taylor, M. C., \& Hall, J. A. (1982). Psychological androgyny: Theories, methods, and conclusions. Psychological Bulletin, 92, 347-366.

Unger, R., \& Crawford, M. (1992). Women and gender: A feminist psychology. New York: McGraw-Hill.

Vonk, R., \& Ashmore, R. D. (1993). The multifaceted self: Androgyny reassessed by open-ended self-descriptions. Social Psychology Quarterly, 56, 278-287.

Whitely, B. E. (1983). Sex role orientation and self-esteem: A critical meta-analytic review. Joumal of Personality and Social Psychology, 44, 765-778.

Zammichieli, M. E., Gilroy, F. D., \& Sherman, M. F. (1988). Relation between sex-role orientation and marital satisfaction. Personality and Social Psychology Bulletin, 14, 747-754. 